Fecha de recepción: marzo 2021 Fecha de aprobación: abril 2021 Fecha publicación: mayo 2021
El Diseño como Tercer Cultura ${ }^{1}$ $5^{\circ}$ Proyecto de la Línea de Investigación No4 Diseño en Perspectiva (CMU-UP)

Daniela V. Di Bella ${ }^{(1)}$

Resumen: El Diseño se ha convertido en un fenómeno global, con un alto poder de persuasión social y cultural (Julier, 2008), que junto a su propio modelo de pensamiento de Diseño, y la potencia de las visiones anticipatorias, puede influir sobre las transiciones sociales y técnicas hacia estilos de vida y escenarios sostenibles. La presente publicación es el quinto Cuaderno de la Línea de investigación No4 Diseño en Perspectiva, Escenarios del Diseño, y pertenece al Proyecto No5 denominado Visiones del Diseño: El Diseño como Tercer Cultura. Continúa las indagaciones citadas desde la más reciente: Problematizar el Diseño para Comprender su Complejidad (Proyecto 4: Cuaderno 105. Di Bella, 2020: 95123) y la necesidad de problematizar al Diseño como parte de la comprensión sistémica de su naturaleza, sus impactos, y del cambio de escala de los problemas en la Gestión de Diseño; Diseñadores Eco-Sociales, y la exploración de lentes potencialmente útiles para el desarrollo de visiones de futuros sostenibles (Proyecto 3: Cuaderno 87. Di Bella, 2019: 55104), El Diseñador como agente de cambio (Proyecto 2: Cuaderno 80. Di Bella, 2018: 173239 y Proyecto 1: Cuaderno 73. Irwin y Di Bella, 2017). Continúa el camino de reflexión e investigación vinculado al Programa Transition Design de la Universidad Carnegie Mellon, dentro de la Maestría en Gestión del Diseño-UP junto con sus acciones de publicación conjunta y dirección compartida que abre un quinto período de estudio de la implementación de la Experiencia.

Palabras clave: Diseño - Futuro - Visiones del Diseño - Diseño para la Transición - Sostenibilidad - Cultura del Diseño - Tercer Cultura - Eco-alfabetización - Transiciones Socio-técnicas - Prospectiva - Investigación en Diseño - Teoría del Diseño.

[Resúmenes en inglés y portugués en las páginas 78-79]

(1) Daniela V. Di Bella. Doctoranda (a nivel Tesis) del PhD en Educación Superior, Facultad de Ciencias Sociales, Universidad de Palermo, donde investiga sobre los escenarios prospectivos del campo del Diseño. Arquitecta, Facultad de Arquitectura y Diseño, Universidad de Morón, (Mejor Promedio 1989), Especialización en Diseño (Summa Cum Laude 1989), Colaboradora / JTP (1985-1989) y del Grupo de Investigación Morfogénesis (19841986) Cátedra Diseño Ivakhoff, Departamento de Vivienda y Medio Ambiente. Magister en Gestión del Diseño (Magna Cum Laude UP 2007) donde investiga sobre Diseño, Arte y Tecnologías. Desde 2014 Directora de la Línea de Investigación No4 Diseño en Perspectiva, bajo el acuerdo académico entre Universidad de Palermo con la School of Design at 
Carnegie Mellon, USA. Profesora Titular de Diseño IV, donde incorpora el tratamiento reflexivo y exploratorio del Diseño para la Transición a la Maestría en Gestión de Diseño, que esta prestigiosa Universidad y el Transition Design Institute (CMU) dictan en su Posgrado. Parte del Cuerpo Académico del Doctorado en Diseño y la Maestría en Gestión del Diseño. Miembro del Plenario de la Comisión de Posgrado. Desde 2006 Directora del Departamento de Producción y Gestión de la Información. Facultad de Diseño y Comunicación de la Universidad de Palermo. Con experiencia de más de 30 años en empresas y clientes, mercado editorial y publicitario, mandos medios de gestión, diseño, producción editorial y arquitectura publicitaria, Docente en otras Universidades e Instituciones educativas. Creadora y Editora de http://metaespac.hypotheses.org ; www.elojosalvaje.com y https://orcid.org/0000-0003-0923-8755

\section{Introducción}

Como se ha venido expresando en los Cuadernos 73, 80, 87 y 105 la Facultad de Diseño y Comunicación a través de la Línea de Investigación $\mathrm{N}^{\circ} 4$ Diseño en Perspectiva Escenarios del Diseño, sus Proyectos, Experiencia e Informes de Impacto, persiguen alinearse con el objetivo central a largo plazo, de graduar generaciones de diseñadores capaces de trabajar eficazmente en equipos transdisciplinarios y transversales que puedan resolver problemas complejos cuyas soluciones contribuyan con gestar transiciones sociales positivas y sostenibles (Irwin, 2017:21). De este modo, a partir de 2014 hasta la fecha, la asignatura Diseño 4 de la Maestría en Gestión de Diseño -cuarta y última cuatrimestral del eje conceptual de Diseño- se desarrolla bajo la Experiencia Diseño en Perspectiva, que incorporó a la currícula de la asignatura, el tratamiento reflexivo, exploratorio y de investigación del Diseño para la Transición vinculado al Programa Transition Design que la School of Design de la Universidad Carnegie Mellon desarrolla a nivel de Doctorado y Maestría en Estados Unidos (Cuaderno 73. Irwin y Di Bella, 2017). La asignatura Diseño 4 se articula en dos fases de trabajo y estudio llamadas a) Clínica o Diagnóstica y b) Crítica o Propositiva, según un Cronograma de estudio dispuesto en seis etapas (1) Definición del Tema y/o Caso, (2) Análisis clínico o diagnóstico del tema y/o caso, (3) Análisis crítico o propositivo del tema y/o caso, (4) Presentación y Defensa del Visionado, (5) Creación de la Comisión Diseño en Perspectiva y Presentación de los resultados a la Comunidad especializada, y (6) Publicación en medios especializados. Estas etapas son consecutivas e integradas a las formalidades de la Línea, los Proyectos y la Maestría en Gestión del Diseño (Cuaderno 80. Di Bella, 2018: 173-239 y Cuaderno 73. Irwin y Di Bella, 2017).

Las actividades centrales que ha implicado esta inclusión son: 1- Incorporación curricular del Diseño para la Transición a la Maestría en Gestión del Diseño a la asignatura Diseño 4; 
2- Implementación de la Experiencia Diseño en Perspectiva dentro y fuera de la asignatura Diseño 4; y 3-Presentación y comunicación del Proyecto y sus productos a la comunidad especializada, debate y publicación, que se realizan (y actualizan) de manera sostenida desde 2014 a la fecha (Cuaderno 73. Irwin y Di Bella, 2017; Cuaderno 80. Di Bella, 2018: 173-239; Cuaderno 87. Di Bella, 2019: 55-104; Cuaderno 105. Di Bella 2020: 95-123) Ver Figuras 1 y 2.

Son testimonios de lo expresado los resultados publicados en sus cinco Proyectos finalizados (1) Diseño para la Transición - Perspectivas del Diseño, (2) Visiones del Diseño I: El Diseñador como agente de cambio, (3) Visiones del Diseño II: Diseñadores Eco-Sociales, (4) Visiones del Diseño III: Problematizar el Diseño para comprender su complejidad y (5) Visiones del Diseño IV: El Diseño como Tercer Cultura, y que fueron presentados en las Comisiones Diseño en Perspectiva durante los Congresos de Enseñanza del Diseño 2015 al 2021 celebrados anualmente en la Semana Internacional del Diseño en Palermo, organizados por la Facultad de Diseño y Comunicación.

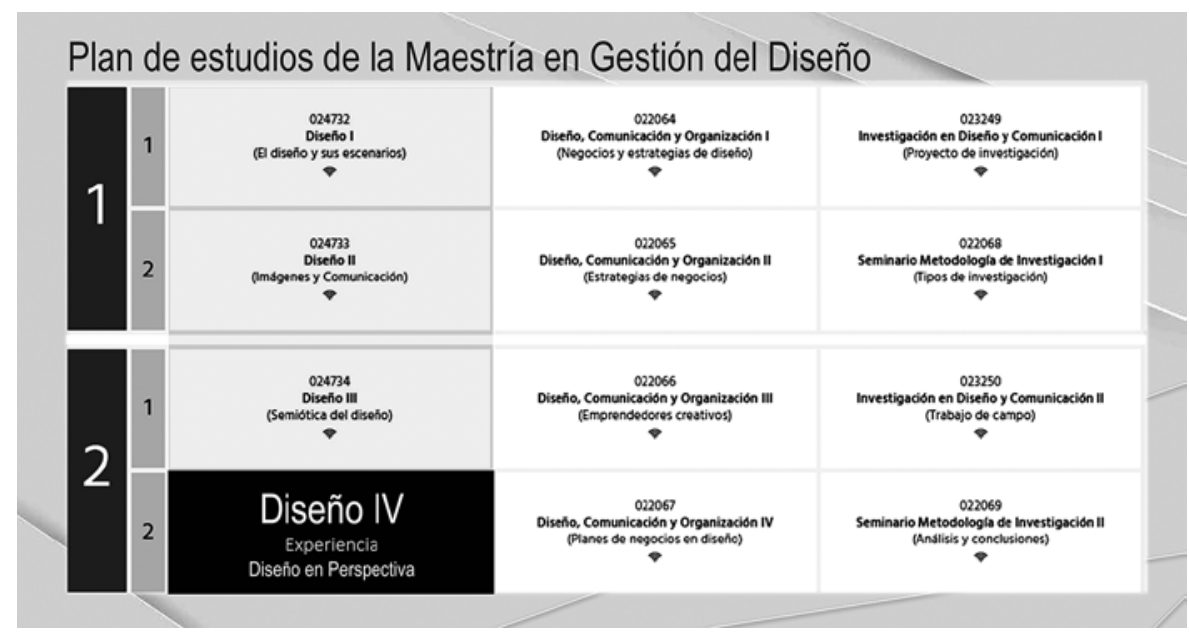

Figura 1. Ubicación de la Experiencia Diseño en Perspectiva dentro de la malla curricular de la Maestría en Gestión de Diseño de la Facultad de Diseño y Comunicación, Universidad de Palermo (Fuente: Daniela Di Bella). 


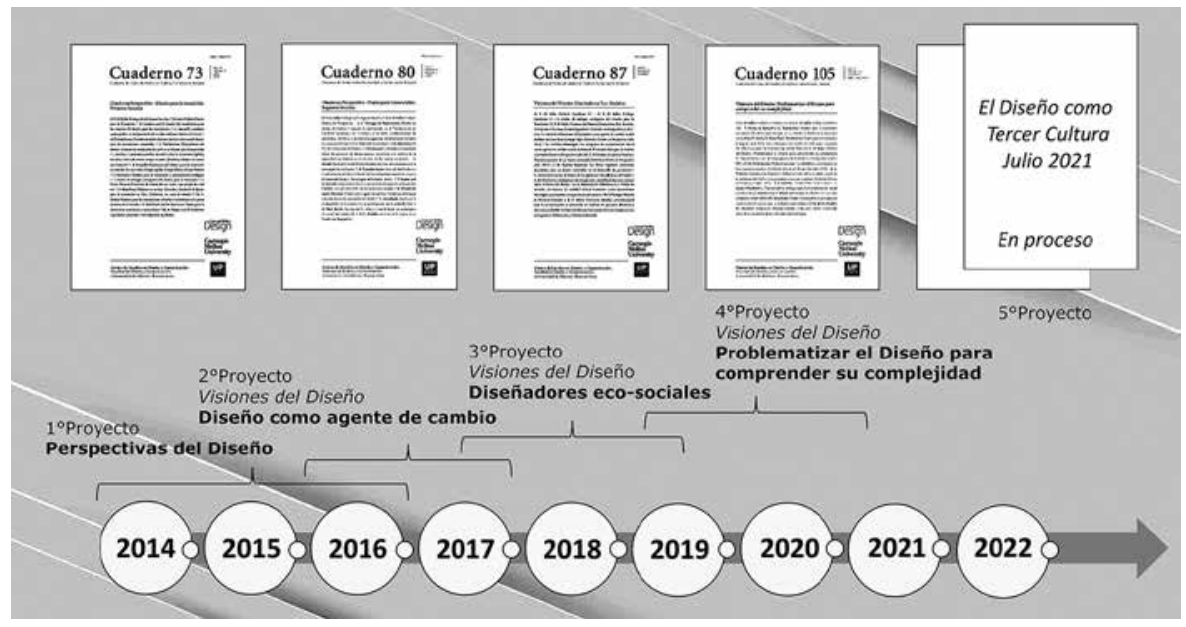

Figura 2. Esquema de los Proyectos de la Línea de Investigación $\mathrm{N}^{\circ} 4$ Diseño en Perspectiva y sus resultados publicados en los Cuadernos de Centro de Estudio en Diseño y Comunicación $N^{\circ} 73,80,87,105$ y el presente volumen (Fuente: Daniela Di Bella).

\section{¿Qué tipo de mundos construyen las cosas que diseñamos?}

I.

La pregunta del título guarda relación en primer lugar con las ideas investigadas por David Allen Kirby donde se pregunta acerca de la potencia que asumen las narrativas y las imágenes -que de estas derivan- en relación con la materialización de futuros. Kirby estudió las potencialidades de las narrativas dentro del campo cinematográfico de ficción, donde el tipo de mundo construido por las cosas diseñadas es decir objetos, espacios construidos, servicios y sistemas, al igual que su utilización y las tecnologías empleadas (que en el cine de ficción son artificiales o simuladas) "se normalizan dentro del texto como objetos prácticos que funcionan correctamente y que la gente realmente utiliza como objetos cotidianos", por lo tanto argumenta que las narrativas del cine permiten al público presenciar simuladamente situaciones de distinta envergadura y tipología que pueden gestar estímulos de acción y realización en la vida real (Kirby, 2010: 41-70).

A estas narrativas, Kirby las denomina prototipos diegéticos, que se han convertido en el motor de la innovación tecnológica (Michael Schrage 2000, en Kirby 2010: 41-70), y pueden ser considerados "artefactos performativos" es decir anticipatorios, u objetos epistémicos apropiados para la investigación dentro y fuera del Diseño, susceptibles de gestar conocimiento desde la práctica (Boserman, 2019). 
...el prototipo toma mayor relevancia y la artefactualidad toma protagonismo, ya sea en términos expositivos o para ser insertada en contextos sociales, acercándose a la idea de artefactos performativos o mediadores (Suchman, Trigg, \& Blomberg, 2002, en Boserman, 2019).

Si llevamos estas afirmaciones demostradas por Kirby al campo del Diseño, al igual que los cineastas de ficción con sus equipos de producción, ingeniería y ciencia, la Arquitectura, el Diseño y los diseñadores trabajan gestando imágenes que definen

- nuestros hábitats o los sistemas que creamos para ser habitados, y

- nuestros hábitos o los estilos de vida que definen el modo en que venimos organizando la vida contemporánea

En síntesis, estas imágenes vienen determinando las narrativas de las sociedades de Occidente, donde según Duncombe los diseñadores "suelen estar en el lado equivocado del espectáculo, ayudando a construir los estímulos que animan a la gente a consumir más" (Duncombe 2007, en Dunne and Raby, 2013:159), asunto que hace necesaria la paulatina reorientación de las prácticas del Diseño hacia objetivos de sostenibilidad.

II.

En segundo lugar hace referencia a la relación sistémica entre Diseño y Futuro (ver Figura 3), cuando la relación diseño y futuro no ha sido vista hasta hoy como un área potencial de estudio e investigación (Cuaderno 105. Di Bella 2020: 108) asunto altamente curioso, ya que el diseño en sí mismo se trata de una dinámica anticipatoria, por lo tanto puede decirse que gesta narraciones que pueden ser entendidas en sentido conceptual como "artefactos performativos".

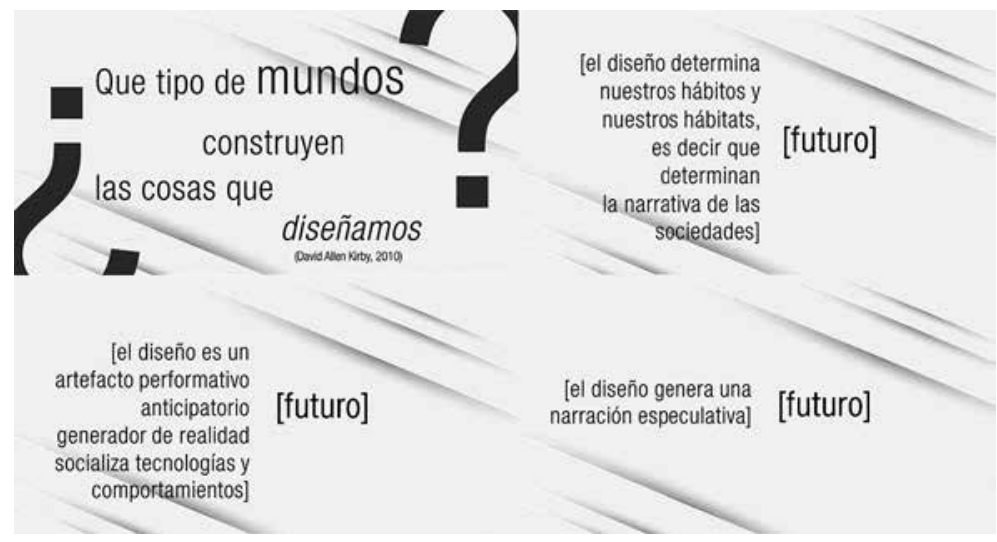

Figura 3. Diseño y Futuro (Fuente: Daniela Di Bella). 
Posiblemente las estrategias para poder comenzar con alguna respuesta positiva y sostenible, pueda estar orientada al estudio del Diseño para la Transición que propone cómo las acciones humanas de modificación (en la que intervienen múltiples partes, entre ellos también los Diseñadores)

a. Se han venido desarrollando en el tiempo (Mapa de Evolución del Problema del pasado al presente) para detectar sus transiciones socio-técnicas en los niveles de Nicho, Régimen y Landscape;

b. Se manifiestan en el presente en vínculo con la escala de los problemas mayores (Mapa del Problema o su conexión con los Wicked Problems) lo que puede definirse como una arqueología del caso-problema (Dorst, 2015), una reformulación de marcos de referencia, una exploración de los temas que subyacen al caso analizado dentro de su contexto o escenario, para estudiar y observar sus áreas y capas de análisis, y comprender que al pertenecer a una escala de problemas mayores, no pueden resolverse dentro del marco de pensamiento que les dio origen (pensamiento lineal). Esta orientación hacia el studio del nivel de los sistemas fue ubicando los problemas hacia las llamadas "ecologías de problemas", denominados wicked problem (Rittel y Webber, 1973) lo que fue implicando a su vez la necesidad de influir sobre los comportamientos y las prácticas sociales (Boks, 2012 y Shove, 2007 en Irwin, Kossoff y Tonkinwise, 2015 y 2020).

c. Involucran a una cantidad de partes interesadas (Mapa de los Stakeholders):

Las relaciones con las partes interesadas (stakeholders) son como el "tejido conectivo", y el hecho de no abordar estas preocupaciones y relaciones complejas constituyen una barrera para la resolución de problemas. Debido a que las relaciones con las partes interesadas impregnan el problema (sistema), de acuerdo al Diseño para la Transición también pueden aprovecharse para diseñar intervenciones orientadas a su resolución (Irwin, 2018).

d. Donde los Diseñadores en su rol de Agentes de Cambio Social, junto a los Stakeholders identificarían los posibles puntos de intervención dentro del sistema, trabajando sobre los puntos de apalancamiento (Leverage Points) propuestos por Donella Meadows (2009) -y a partir del Diseño Colaborativo y el Co-Diseño (Sanders y Stappers, 2008)- podrían formular las gestiones que definan la toma de las decisiones apropiadas, para poder influir en el curso de estas transiciones (no dejarlas a su libre evolución), y donde Diseño y diseñadores deben aprender a trabajar guiando a otros agentes en forma dialógica (Manzini, 2015: 66 y 88);

e. Luego Diseñadores y Stakeholders, podrían crear narrativas traducibles en representaciones e imágenes de futuro intencionadas (Visiones de Diseño) con el fin de influir y orientar cambios hacia escenarios sostenibles de largo alcance, que permitan migrar hacia una sociedad regenerativa (Manzini y Jegou, 2003: 16-17), cuyos objetivos se orienten por 
la calidad del entorno, y donde las empresas y las organizaciones se conviertan en agentes de sostenibilidad ecológica, social y económica.

Estas prácticas especulativas tratan situaciones que se reflejan en el hoy y se extrapolan al mañana, a través de guiones o historias sobre los tipos de experiencias y rituales sociales que podrían rodear a la situación futura diseñada, ya que estas visiones no pueden existir fuera de un contexto de uso imaginado (hábitos y hábitats), donde la especulación se uniría al Diseño (y a la ciencia) dentro de un proceso productivo y/o de gestión, donde se pueden crear, imaginar y visionar narrativas y escenarios para otros contextos de vida (Bleecker, 2009):

Los buenos diseños se convierten en nuestros hábitats y hábitos que pueden determinar futuros caminos para nuestras sociedades. Todo esto implica que el diseño puede desempeñar un papel más central en el discurso de la transición (Irwin, Kossoff, Tonkinwise, 2015 y 2020).

Estos objetos epistémicos o anticipaciones, son parte del visionado de futuros sostenibles que dependen del modelo heurístico o framework del Diseño para la Transición estructurado en cuatro etapas interrelacionadas: (1) Visiones para la transición, (2) Teorías del cambio, (3) Postura y mentalidad, y (4) Nuevas maneras de diseñar orientada a largos horizontes de tiempo (Irwin 2011; Irwin et al, 2015). Este modelo apela al carácter "generativo" del diseño, en tanto visiones que van desplegando el estudio de una especulación prospectiva preferible de futuro gestada a través de las "lentes" potencialmente útiles para el desarrollo de visiones de futuros sostenibles (Thackara, 2005: 1-8; Lockton y Candy, 2018) (Se pueden ver las Figuras $4 a, 4 b, 4 c, 5 a, 5 b, 6 a, 6 b, 7 a$ y $7 b$ donde se exponen casos tratados por estudiantes de la Experiencia Diseño en perspectiva 2020). 


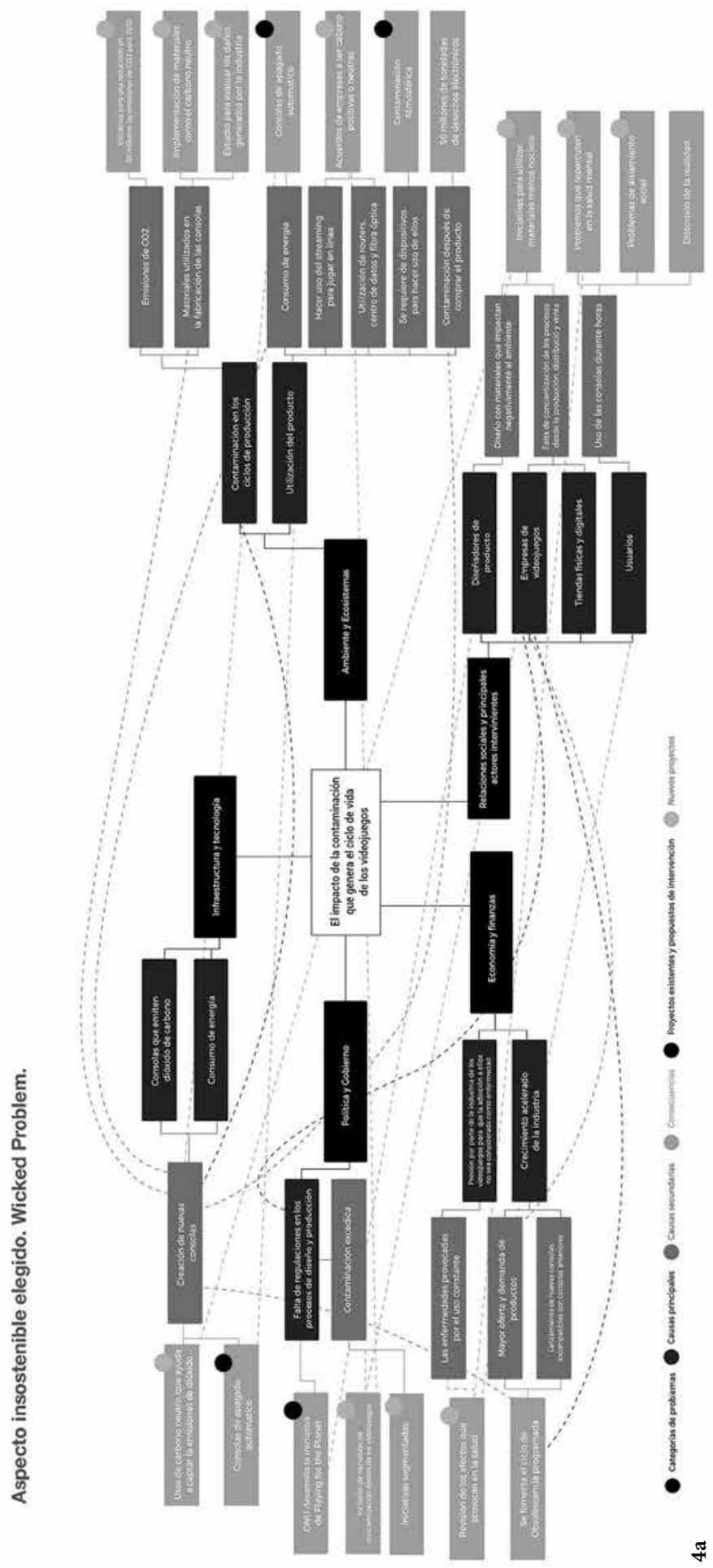




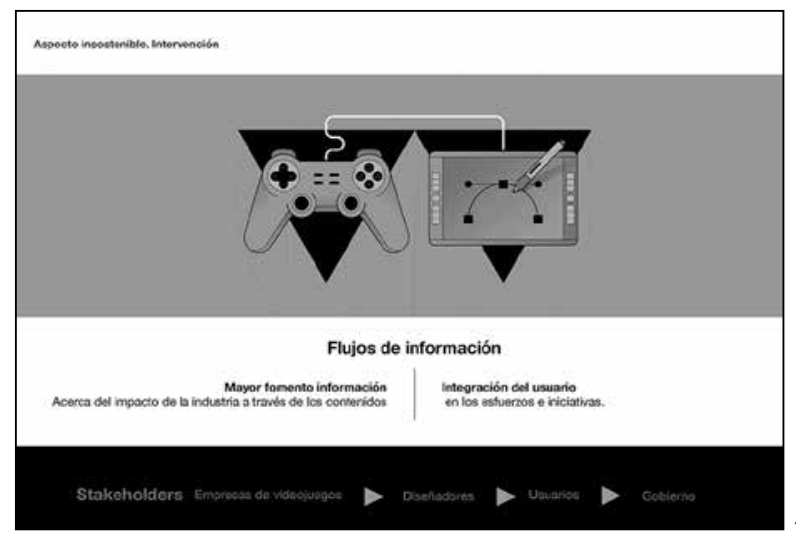

$4 b$

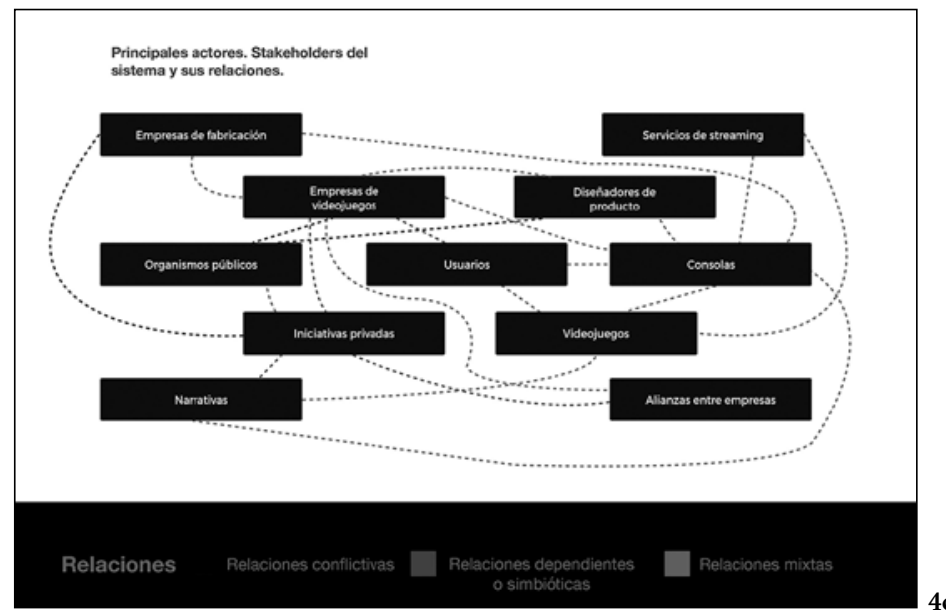

Figuras 4a, 4b y 4c. Diagrama del Análisis de la conexión con el Wicked Problem, extracción de los Stakeholders del aspecto insostenible analizado del caso elegido por Ernesto Monzón relativo a los aspectos insostenibles de la industria de los videojuegos, que genera ingresos multimillonarios, es centro de inversiones por la escalabilidad y penetración del negocio. Basado de un profuso clipping de medios y autores consultados, analiza sus impactos negativos en el medioambiente como los sociales, psicológicos y médicos (consumo energético, huella de carbono, aspectos adictivos, sedentarismo, stress, descuido de las actividades académicas, sobrepeso y obesidad, entre otras). Analiza la interconexión de los diferentes actores en el problema, cuyas relaciones creadas van desde el aspecto tecnológico y desarrollo de nuevos productos incidiendo sobre el eje medioambiental a través de la contaminación. Se relaciona con el uso del producto, donde el eje de economía y finanzas juega un papel fundamental en el aumento de la demanda de productos a la industria, generando mayor consumo, cerrando un ciclo de impactos sobre el medioambiente. El eje política y gobierno tiene una conexión con los principales actores como los usuarios y las compañías creadoras del producto, todas las interconexiones indican un flujo constante entre la demanda, la producción, el consumo y los impactos. Para su propuesta de Visionado, interviene sobre el punto de apalancamiento de los flujos de información, para utilizar la tendencia que dice que los clientes de hoy esperan que las empresas entreguen valor de una manera social y ambientalmente responsable, apuntando al cambio del consumidor, donde la necesidad de un consumo socialmente responsable no es un asunto generacional, sino que a través de la comunicación es posible orientar la preferencia de productos que cumplan con criterios ecológicos, responsabilidad y un compromiso social. Organiza las acciones apuntando a la transformación cultural, social y económica transversal a los sectores. [Experiencia Diseño en Perspectiva 2020] (Fuente: Ernesto Monzón). 


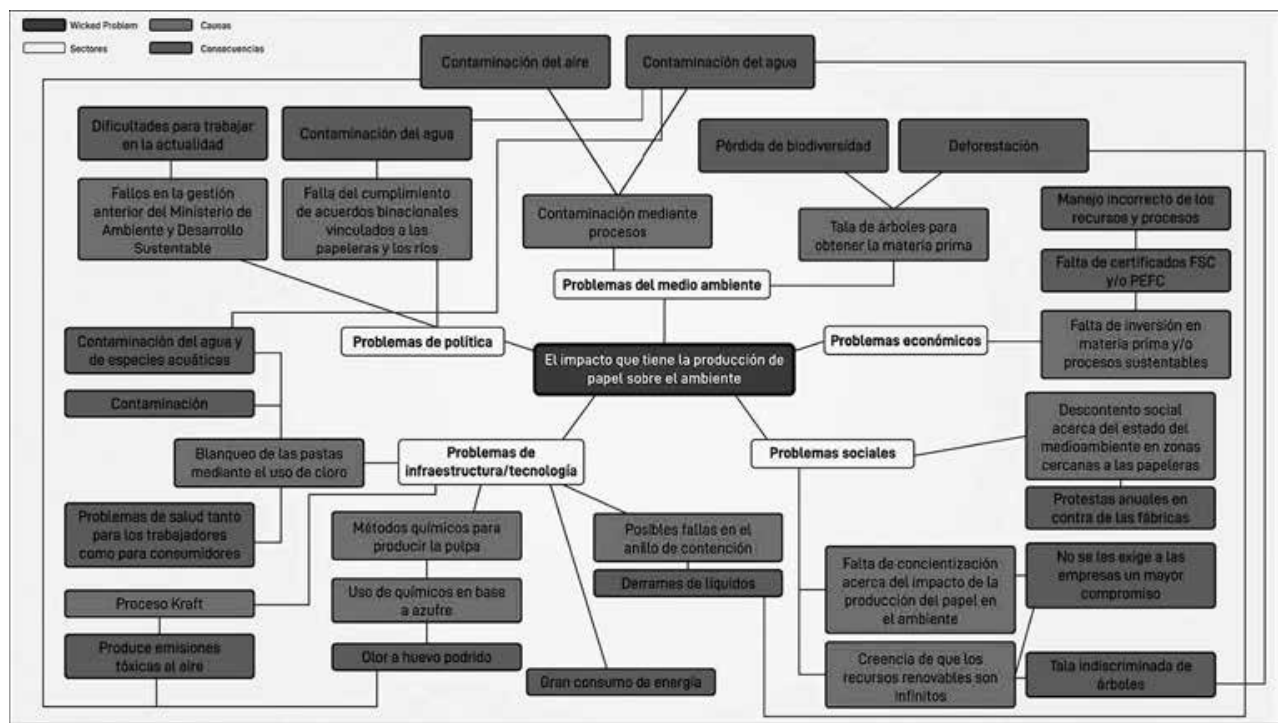

$5 a$

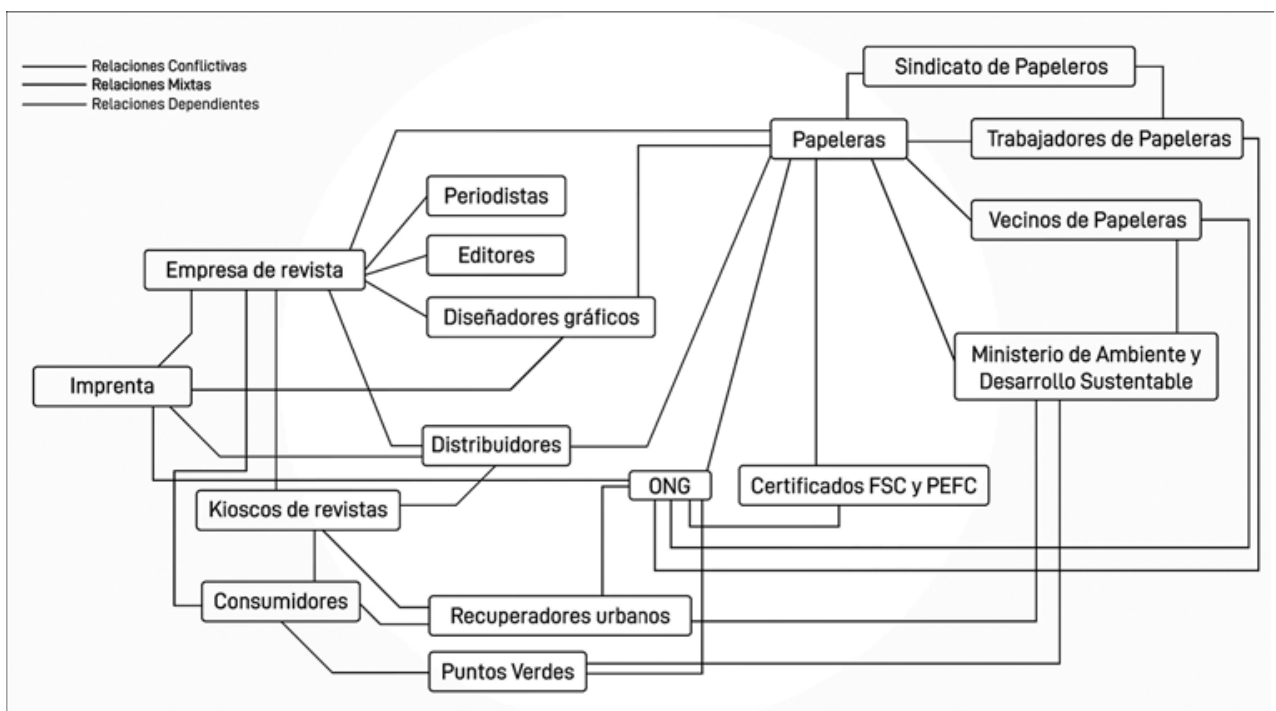

$5 \mathbf{b}$ 


\section{[Insostenibilidad]}

ASPECTOS INSOSTENIBLES: ređucir considerablemente la generación de desechos

Los productos con base en Tecnología led al cumplirse su ciclo de vida útil, o si por algún desperfecto la lámpara deja de funcionar. Este se desecha en su totalidad.

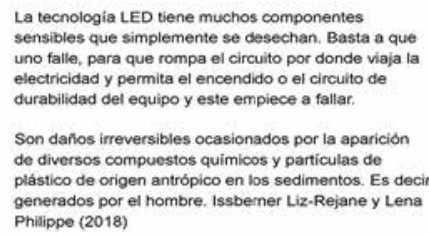

Son daños irreversibles ocasionados por la aparición de diversos compuestos quimicos y particulas de plástico de origen antrópico en los sedimentos. Es decir plastico de origen antropico en los sedimentos, Es decir Philippe (2018)

$6 a$

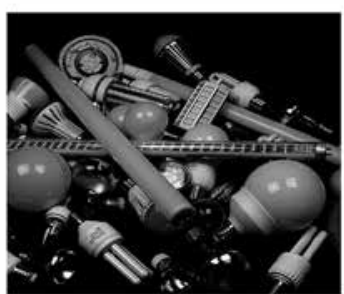

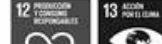
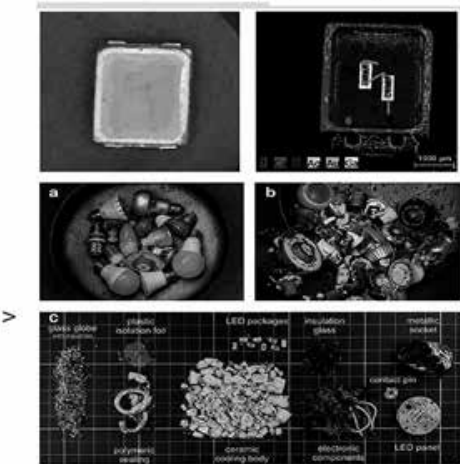

Figuras 5a y 5b (p. 62). Diagrama del Análisis de la conexión con el Wicked Problem, y extracción de los Stakeholders del caso elegido y analizado por Agustina Andrietti relativos con la interpretación de los aspectos insostenibles de la producción editorial e impresa de una revista líder del mercado musical. Centrada en los aspectos de la producción papelera analiza los impactos a través de un clipping de medios del que extrae los aspectos esenciales relacionados con la crisis medioambiental, la deforestación, la contaminación de las tintas, el excesivo consumo de agua, los desechos químicos, la contaminación del agua y márgenes de ríos nacionales en zonas de instalación de papeleras foráneas, las regulaciones y leyes que surgen de la intervención de los distintos actores, intervenciones políticas, ministeriales y de organizaciones no gubernamentales, etc. Para su propuesta de Visionado, basada en el nivel de intervención que modifica parámetros, constantes y números, apuntó a un cambio de modelo de negocio y de consumo, en pos de la reducción de insumos y desechos, sostenido sobre las ideas de la creciente desmaterialización del diseño. [Experiencia Diseño en Perspectiva 2020] (Fuente: Agustina Andrietti).

Figuras 6a y 6b (p. 63 y 64). Analisis de los aspectos insostenibles y Diagrama del Análisis de la conexión con el Wicked Problem del caso elegido y analizado por Carolina Levy relativos a un sistema de iluminación bajo tecnología led, cuyas aplicaciones en ámbitos de oficina sintoniza con los relojes biológicos de los ocupantes mejorando la experiencia de uso. Analiza los circuitos de producción y consumo del sistema, sus materiales y el momento en que el sistema debe ser por entero desechado frente a las fallas de la obsolescencia programada que marca los ciclos de renovación del sistema. Basa su propuesta de Visionado en el modelo cradle to cradle (de la cuna a la cuna) ya que potencialmente el $95 \%$ de los desechos del sistema podrían ser reciclados, ya que frente a las fallas técnicas el sistema de por si debe ser reemplazado por entero, convirtiéndose en basura electrónica y de agentes químicos (metales raros) al superarse los 5 años de vida útil estimado al sistema de iluminación. El Visionado implicaría la reorganización del sistema de producción, apuntando a su circularidad a través de las múltiples alianzas basadas en distintos tipos de incentivos con las empresas que hoy recolectan, clasifican, reciclan y reprocesan los desechos, lo que impactaría sobre los sistemas de regulación, sobre la producción y duración del sistema-producto y sobre la cultura de la empresa fabricante [Experiencia Diseño en Perspectiva 2020] (Fuente: Carolina Levy). 


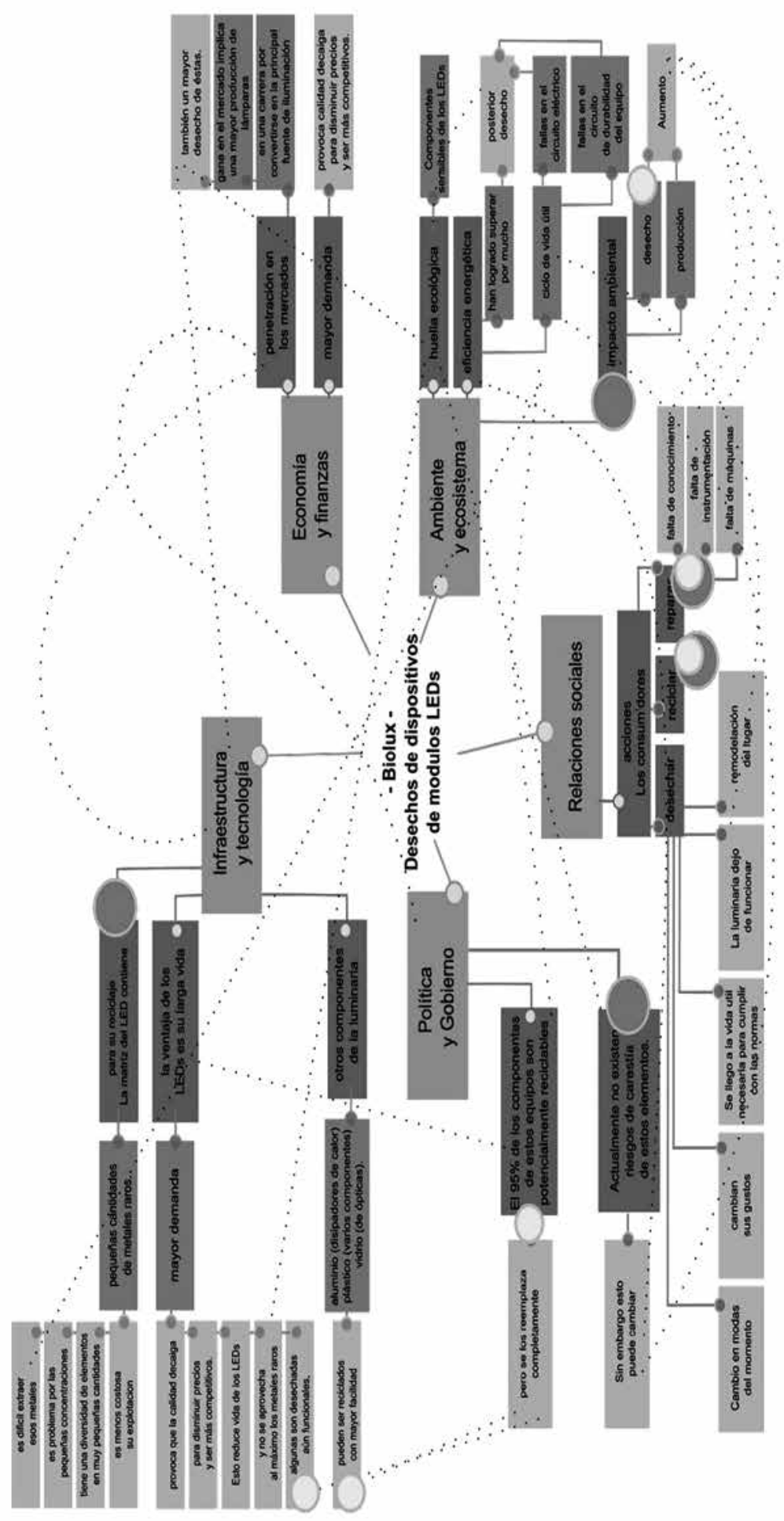




\section{Storyboard}

¿Qué pasaría si intervenimos los kilómetros clave del río Bogotá?

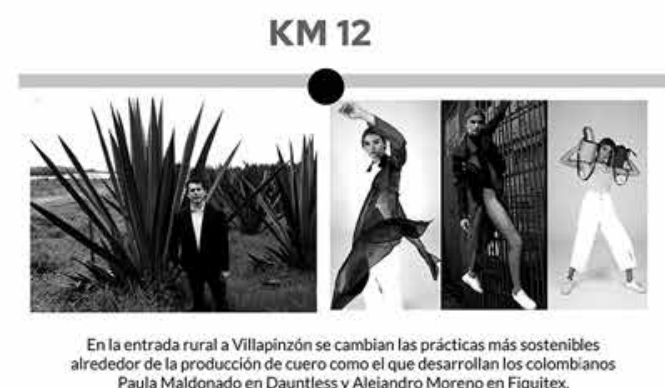

Paula Maldonado en Dauntless y Alejandro Moreno en Fiquitex
KM 182 AL 272

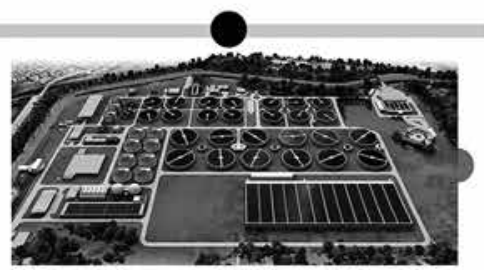

Entra en funcionamiento la planta de tratamiento de aguas residuales el Salitre en la ciudad de Bogotá proyectada para el 2021

\section{KM 304}

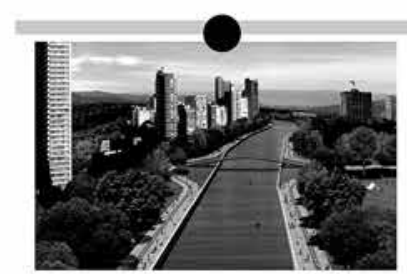

Se retoma la propuesta del ex alcalde Enrique Peñalosa: el Gran Proyecto det Rio Bogots Una ampliación de 3 veces en su ancho y lo protundice al doble, la generación de un malecón que lo contenga y un espacio donde a lo largo de caminar alrededor de ét.

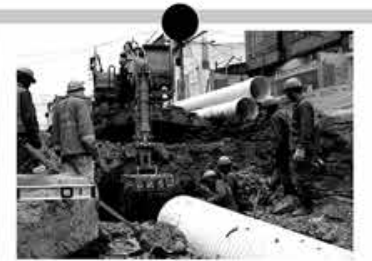

La empresa de Acueducto y Alcantarillado de Bogotá realiza modificaciones sobre la red de alcantarillas de la ciudad para evitar que desemboquen en el rio Bogot.

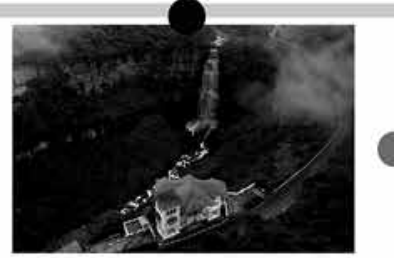

Se promueve el turismo en el Salto de Tequendama; recordando la importancia que tiene este lugar para la capital colombiana en cuanto a recurso hidrico e

\section{Objetivos del desarrollo sostenible. PNUD}

Contaminación río Bogotá

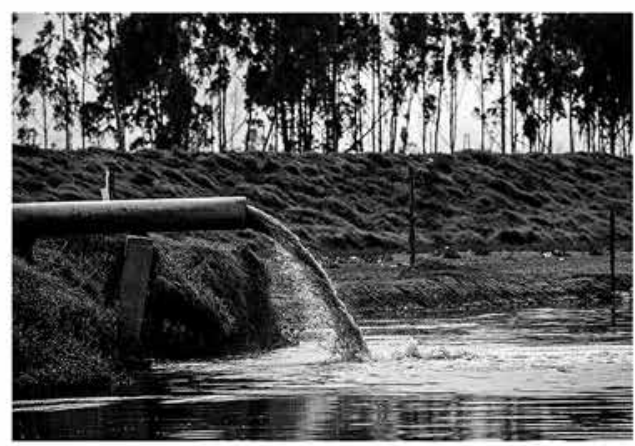

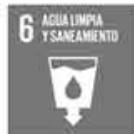
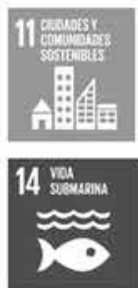
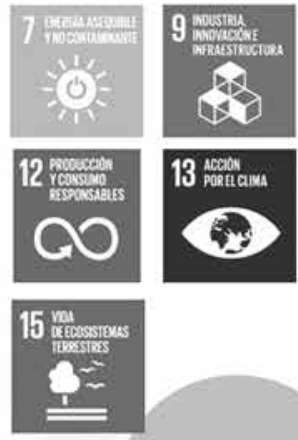


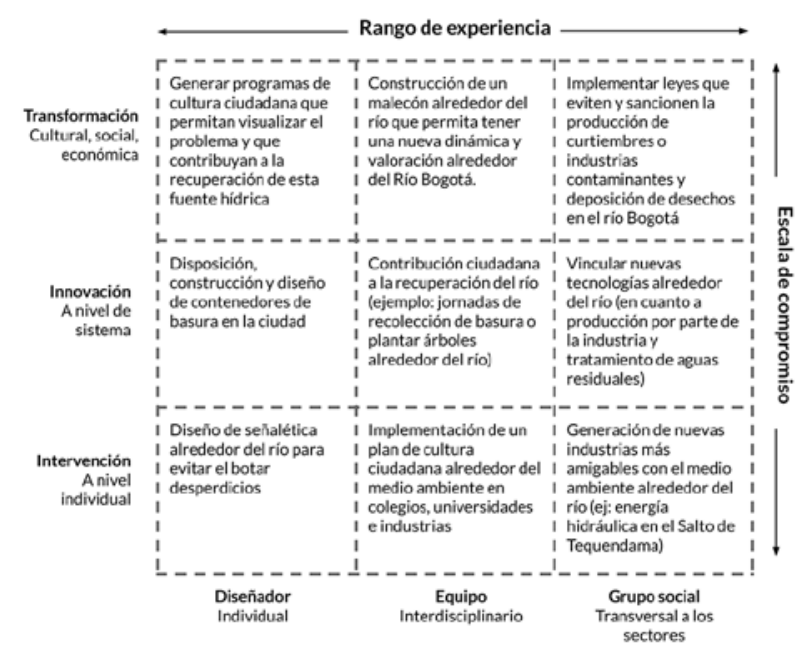

\title{
Pathways of Social Design
}

\author{
Contaminación del Río Bogotá
}

$7 \mathbf{b}$

Figuras 7a (p. 65) y 7b. Diagrama del Pathways of Social Design, Storyboard en posibles pasos de la propuesta de visionado e impacto sobre los Objetivos del Desarrollo Sostenible del caso elegido y analizado por Mariángela Orozco, relativo a los aspectos insostenibles del Río Bogotá, Colombia. Para su propuesta de Visionado retoma y analiza una propuesta de saneamiento que no prosperó, basada en su ampliación y reactivación económica como polo turístico, con el fin de motorizar un proceso de descontaminación de las aguas, y recuperación de su valor histórico e hídrico. Analiza los aspectos que deberían ejecutarse en el presente como p.ej. finalizar la planta de tratamiento de aguas residuales que evitaría la llegada de toneladas de desechos que llegan directamente al río junto a la formulación de leyes medioambientales. A mediano plazo detecta la necesidad de intervenir sobre las curtiembres que siendo que son una de las industrias más destacadas de la zona, resultan de las más contaminantes, orientándolas hacia nuevas alternativas menos agresivas. En largo plazo depende de la vinculación y compromiso total de los 47 alcaldes y sus municipios o ciudades correspondientes como líderes de la comunidad, para que puedan generar propuestas articuladas entre municipios o alcaldías alrededor del río y cada sector pueda aportar a esta problemática de manera positiva. Al abordar el Pathways of Social Design la problemática se centró en cómo se puede escalar una solución de acuerdo al rango de experiencia y la escala de compromiso de los actores. La estudiante se pregunta ¿Cómo cambiar los estilos de vida y el cambio de nivel del sistema para el logro de un futuro sostenible?, donde justamente los deseos, los influenciadores, los motivadores y las necesidades generan incógnitas a través de los tres sistemas identificados en la problemática alrededor de la contaminación del Río Bogotá: sistema de consumo, sistema de la vida y sistema de trabajo deberían volverse más concientes y más responsables. Para ello plantea un esquema de storyboard, con una intervención en los kilómetros clave de la fuente hídrica. [Experiencia Diseño en Perspectiva 2020] (Fuente: Mariangela Orozco). 


\section{III.}

En tercer lugar hace referencia al Antropoceno. Con el comienzo de la industrialización a fines del 1800, y a partir de los modelos asumidos de producción y consumo -que con el tiempo se han ido acelerando y complejizando cada vez más- se fueron naturalizando procesos, procedimientos, tecnologías, materiales y circuitos, donde no se advirtieron ni se pensaron debidamente las consecuencias sin precedentes que a largo plazo estas acciones iban a estar provocando sobre el planeta y en sus condiciones de habitabilidad. Las modificaciones, alteraciones y agresiones sobre la naturaleza desatan problemas sistémicos e interconectados que se vienen anunciando desde el campo de la investigación y la ciencia desde mediados de 1900 (The Limits to Growth Report, 1972 y Update a los 30 años del Informe $e^{2}$, cuyas respuestas son lamentablemente muy lentas, representando grandes riesgos $\mathrm{y}$ dificultades para las sociedades actuales y futuras. Muchas las hemos venido constatando con un alto nivel de incertidumbre, debida cuenta la actual pandemia del Covid-19 desatada a finales de 2019 y que aún -al cabo de más de un año y medio de curso- no se logra controlar a nivel global, acontecimiento que ha fracturado la línea de régimen dentro de los sistemas de organización de cada uno de los países del globo (Ver en este Volumen COVID 19 in the US through the lens of Transition Design Irwin, Kossoff, Gasperak, 2021: 29-51).

Hemos ingresado al Antropoceno ${ }^{3}$, lo que indica un cambio profundo e irreversible en los sistemas de la tierra constatable en una huella geológica alarmante, determinada por nuestras prácticas y actividades de los últimos 200 años. Debemos concientizarnos y educar en la toma de conciencia de que estamos siendo un tipo de humanidad cuya depredación se constituye en la responsable de un posible colapso del planeta ${ }^{4}$.

Esto se debe:

(a) Al tipo de actividades iniciadas con la Revolución Industrial y la utilización de energías fósiles (Rejane Issberner y Léna, 2018: 7-10, UNESCO 2018);

(b) Nuestro modo de organización cuya base filosófica reduce los dominios humanos, sociales y ecológicos a valores de capital financiero, o Capitaloceno $0^{5}$ que pretende la acumulación desmedida de capital, la maximización y crecimiento continuo de las ganancias, lo que conduce de manera irremediable a profundos problemas socio-ambientales (Boehnert, 2019: 139-140). Este modelo de pensamiento ha conducido a los denominados Wicked Problems cuya definición, según explica Terry Irwin (2019) se vinculan con: "el cambio climático, la seguridad hídrica, la pobreza, el crimen, la migración forzada y la pérdida de biodiversidad (que) son problemas de sistemas" y constituyen un desafío por varias razones: 1) involucran a múltiples partes interesadas con agendas conflictivas; 2) poseen muchos límites disciplinarios; 3 ) están mal definidos y las partes interesadas rara vez comparten una comprensión del problema; 4) el problema está cambiando y evolucionando continuamente; 5) los problemas existen en múltiples niveles de escala y son interdependientes e interconectados; 6) cualquier intervención (intento de solución) en una parte del sistema, se ramifica en otra parte de manera impredecible; 7) las intervenciones toman mucho tiempo para evaluar y los problemas, mucho tiempo para resolver (Irwin, 2018). (c) Los procesos de hiperaceleración sucedidos con y desde la Segunda Guerra Mundial que demuestran cómo se habrían disparado "todos los indicadores disponibles sobre el con- 
sumo de recursos primarios, utilización de energía, crecimiento demográfico, actividad económica y deterioro de la biósfera" y la alteración de cuatro de los nueve límites del planeta ${ }^{6}$ : el clima, la alteración de la cobertura vegetal, la erosión de la biodiversidad o la desaparición de especies animales, y la alteración de los flujos biogeoquímicos, en los que los ciclos del fósforo y el nitrógeno desempeñan un papel esencial (Rockström y Steffen en Rejane Issberner y Léna, 2018: 7-10, en UNESCO, 2018).

(d) A la Tecnósfera, que al igual que Antropoceno constituye una nueva palabra que va adquiriendo cada vez más espacio y reconocimiento dentro de la comunidad científica, aunque muchas veces se han prestado a controversias, polémicas y discusiones, aunque los testimonios de su existencia son parte de nuestra vida contemporánea. Al igual que la biósfera que engloba el conjunto de los organismos vivos del que los humanos formamos parte, se denomina Tecnósfera

Al conjunto de objetos tecnológicos producidos por la humanidad, pero no únicamente (...) la componen nuestras máquinas, los seres humanos, y todos los sistemas sociales y profesionales que permiten interactuar con la tecnología: fábricas, escuelas, universidades, bancos, sindicatos, partidos políticos e Internet (...) también los animales domésticos que criamos en cantidades enormes para alimentarnos; las plantas que cultivamos para nuestro sustento y el de nuestros animales; y los suelos agrícolas cuyo estado natural hemos modificado en gran parte para el cultivo de esas plantas (...) también las carreteras, redes ferroviarias, aeropuertos, minas y canteras, campos de petróleo y gas, ciudades y obras hidráulicas. Todos esos componentes de la tecnosfera han generado ingentes cantidades de desechos que se acumulan en vertederos y contaminan el aire, el suelo y el agua (Definición de Peter Haff, Duke University, Correo de la UNESCO 2018:15-16).

La gran diferencia entre la biósfera y la tecnósfera, es que la primera recicla cada uno de sus desechos biológicos, en cambio la tecnósfera ninguno, se la considera parasitaria de la biósfera ya que posee una evolución conjunta de los sistemas humanos y los tecnológicos que los hace interdependientes, ha permitido el alto crecimiento demográfico de los tiempos recientes, ya que sostiene gran parte de las actividades humanas y sus desechos han alcanzado proporciones siderales, por lo tanto los impactos de la tecnósfera sobre la biósfera ponen el riesgo la habitabilidad del planeta (Jan Zalasiewicz, Geólogo, Universidad de Leicester en Correo de la UNESCO 2018:17).

Habitar el Antropoceno nos indica que hemos pasado los limites de modo irremediable y que:

El mundo deberá emprender transformaciones "rápidas" y "sin precedentes" en sectores como la energía, la industria o las infraestructuras si quiere limitar el alza de las temperaturas a $1,5^{\circ} \mathrm{C}$, meta que contendría eventuales daños irreversibles en el medio ambiente y en la calidad de vida de la especie humana (...); "Si no actuamos ahora, nos dirigimos hacia un mundo en el que estaremos siempre gestionando crisis" (Diario La Nación del 8 de octubre de 2018: Última llamada de la ONU para evitar un cambio climático catastrófico) ${ }^{7}$. 
Para esto el Diseño y los diseñadores somos parte activa de la mayoría de las crisis sociales y ambientales definidas por el Antropoceno, y debemos operar un cambio de mentalidad ya que nuestras prácticas son parte de un modelo reduccionista y han sido pensadas para un contexto que ya no existe.

(...) el cambio climático va crear nuevos peligros y aumentar los que ya se ciernen sobre los ecosistemas naturales y humanos (...) esos riesgos están desigualmente repartidos y en general afectan más a las personas y grupos desfavorecidos. Sin embargo, no resulta facil encontrar una solución a este problema, habida cuenta de lo heterogéneos que son los países en función de su nivel de desarrollo, extensión territorial, población, recursos naturales, etc. (Rejane Issberner y Léna, 2018: 9, UNESCO 2018).

Si duda, el desafío central de la era actual es la transición hacia la sostenibilidad y debe definirse en los términos más amplios posibles en todas sus capas política, social, económica, cultural, científica y tecnológica: cada dimensión de los asuntos humanos se ve desafiada por la necesidad de pasaje hacia la transición y, a medida que se van alcanzando puntos críticos (cambio climático, pandemia, inequidad, agotamiento de recursos, pérdida de biodiversidad, etc.) aumenta la urgencia con la que se debe gestionar.

Según Capra (1997) las cosmovisiones de las personas describen y predicen la realidad y, por lo tanto, determinan cómo perciben y participan en el mundo, por eso es importante orientarse hacia una visión holística que aborde los desafíos a nivel de los sistemas. Por lo tanto urge un cambio de paradigma, generar un nuevo mindset ${ }^{8}$, que pase de una mirada antropocéntrica (dominante desde hace más de 500 años) hacia un enfoque ecocéntrico (Fry, 2004), asunto que implica -cambiar la mentalidad- para apoyar imperativos ecológicos (Orr, 2002: 4).

Es importante que seamos conscientes de las contradicciones que se dan entre nuestros deseos inmediatos y lo que sabemos del cambio climático. Necesitamos otro tipo de sociedad. No podemos mantener la forma actual del capitalismo durante 100 o 200 años más. Seria acertado deslegitimar el consumismo y reeducar nuestros deseos. Tenemos que asumir la responsabilidad de transmitir este mensaje en las escuelas y universidades (Entrevista al historiador de la Universidad de Chicago Dipesh Chakrabarty realizada por Shiraz Sidhva. En El Correo de la UNESCO, 2018: 14).

El Diseño alineado ecológicamente posee características amplias ya que "une la ciencia y el diseño, la política y la economía” (Orr, 2002: 4), estaría orientado a colaborar con la instauración del Ecoceno, o una nueva época cuya ontología, epistemología y ética surgen de formas de conocimiento comprometidas ecológicamente (Orr, 1992; 2018), y que respeta los principios de (1) interdependencia, (2) reciclaje, (3) asociación, (4) flexibilidad y (5) diversidad (Capra, 2009: 307-314) (Ver Figuras 8 y 9). 


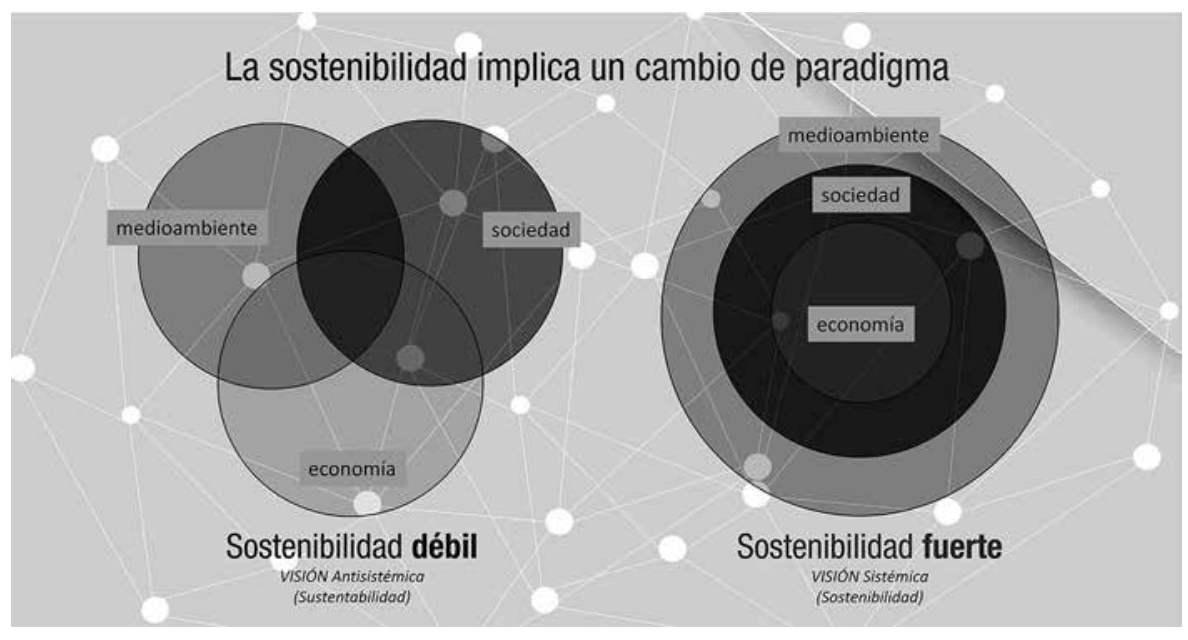

8

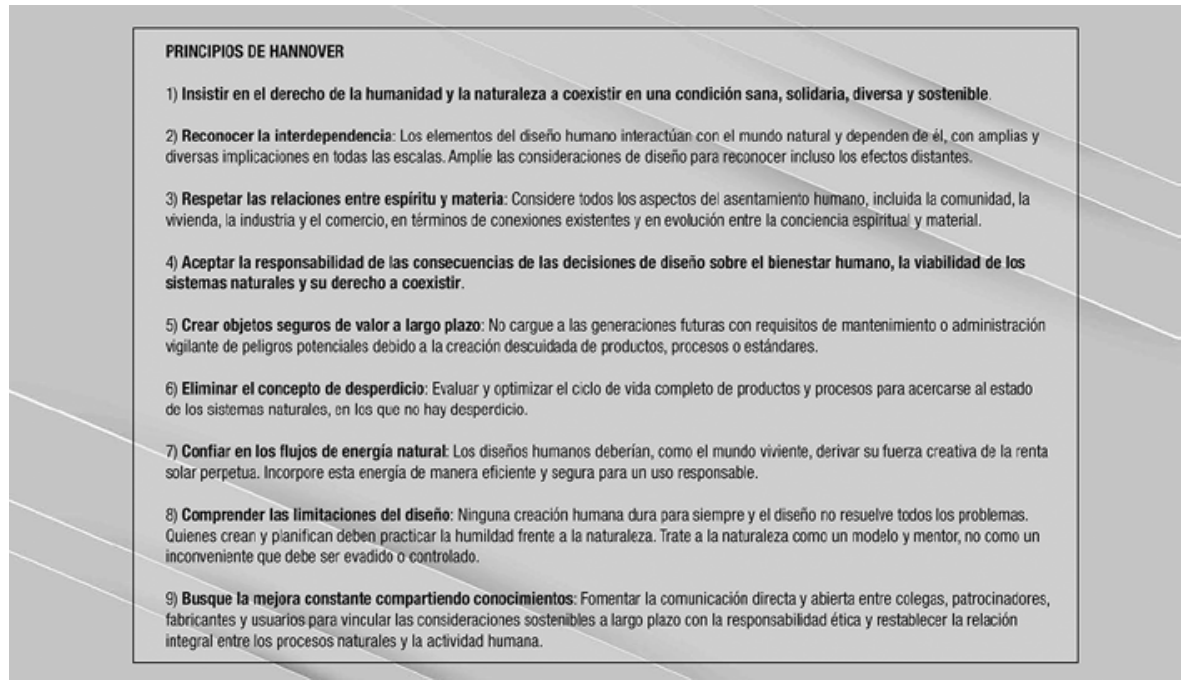

9

Figura 8. Urge cambiar de un paradigma antropocéntrico hacia uno ecocéntrico. El término sostenible, excede el marco de lo puramente ambiental, hace referencia a todas las situaciones sociales y ambientales que se vuelven insostenibles en cualquier plano del ejercicio de las actividades humanas y naturales (inequidad, contaminación en lugares de trabajo y/o de vivienda, hacinamiento y trabajo esclavo, matanza indiscriminada de especies por pieles, cuero, comercio clandestino, etc.; falta de protección social y legislación laboral, discriminación, etc.; por nombrar solo algunas) (Naredo Pérez, 2004, pp. 7-18) (Fuente: Naredo Pérez, modificado por Daniela Di Bella).

Figura 9. Principios de Hannover de William McDonough y Michael Braungart.“...estamos advirtiendo de manera reciente e inesperada que se requiere de una inusitada sensibilidad y conocimiento para asumir "que las pequeñas acciones de diseño pueden tener grandes efectos", ya que el "ochenta por ciento del impacto ambiental de los productos, servicios e infraestructuras que nos rodean se determina en la etapa de diseño" (Thackara, 2005, pp. 1-8). (Fuente: William McDonough y Michael Braungart, Exposición Mundial 2000, Humanidad, Naturaleza y Tecnología, modificado por Daniela Di Bella). 


\section{IV.}

En cuarto lugar hace referencia al Diseño entendido como una Tercer Cultura. Dilnot hacia mediados de los 80 , hacía referencia a Snow quién creo a "las dos culturas" para indicar la brecha entre las artes y las ciencias entre las que se ha situado al Diseño dentro de la Academia, aspecto conceptual que ha repercutido históricamente en la falta de la dimensión social del Diseño. Curiosamente el Diseño, desde su mirada más antropológica, es una actividad de modificación que se desarrolla dentro de la sociedad, pero en la búsqueda de la comprensión de los fenómenos que interesan a la disciplina, se lo ha centrado más que nada en aspectos instrumentales, técnicos y funcionales, alejándolo de manera determinada de los aspectos sociales del Diseño, o de la sociología del Diseño, entendiendo esto como un problema cultural de las tradiciones teóricas que fueron delineando de que se trata diseñar. Esta situación ha generado un divorcio en las lecturas del vínculo entre lo diseñado y el diseño, como revelador de las relaciones Diseño-Sociedad, y en esto el desarrollo de los posibles vínculos del Diseño con los aspectos políticos de su ejercicio -es decir ha obturado la posibilidad de desplegar las capacidades politicas del diseño (Escobar, 2016: 43)- lo que resulta una paradoja, ya que los que diseñamos sabemos que nuestra tarea es una actividad multidimensional que sintetiza aspectos muy heterogéneos, donde los aspectos operativos relativos a la cultura material no alcanzan para definir la verdadera dimensión que significa la transformación material que el Diseño representa sobre las relaciones sociales, y que están provocadas por y a través de la modificación de su entorno material (Dilnot 1982: 1-40). (Ver Figura 10)

El significado social del diseño se encuentra entonces dentro de esta noción extendida de forma, una noción que se extiende desde la formación material de los productos y otros aspectos del medio ambiente (en el contexto de la comprensión del papel social que desempeña, de ahí la necesidad de un teoría paralela de la actividad de la cultura material en relación con la organización social) hasta la actividad de formarse como tal (donde el diseño modela la praxis humana en general (...)

El diseño es socialmente significativo, ya que modela la síntesis, la encarna materialmente y actúa como un modelo de síntesis en el sentido más amplio. Sobre todo, el diseño modela en la actualidad la síntesis de requisitos técnico-instrumentales y simbólicos interactivos-comunicativos, y así nos da un modelo concreto de cómo estos reinos aparentemente antitéticos de la experiencia humana pueden unirse (Dilnot 1982: 1-40). 
El Diseño como Tercer Cultura se encuentra entre los dos polos de la Ciencia y las Humanidades y está en el centro de las preguntas relacionados con la posibilidad, la viabilidad y lo deseable

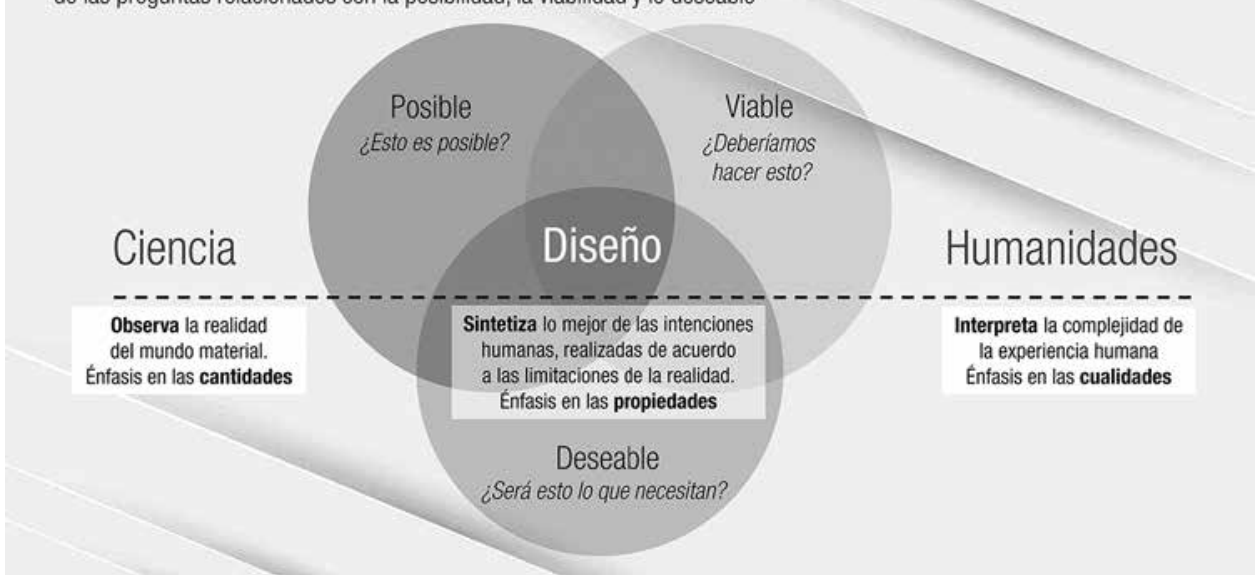

Figura 10. El Diseño como Tercer Cultura. Diagrama que coloca el diseño entre los dos polos de la ciencia y las humanidades. Basado en un concepto propuesto por el Helsinki Design Lab en su publicación de 2013 titulada "Recetas para el cambio sistémico" (Fuente: Terry Irwin, modificado por Daniela Di Bella).

De acuerdo a la investigación de Guy Julier pocas industrias de Occidente han crecido en términos de presencia económica e intercambio cultural como lo ha hecho el diseño en las últimas décadas, siendo las actividades de branding y la construcción de valores-signo, las que reconfiguraron la publicidad y la comunicación, convirtiéndolo en una disciplina con un alto poder persuasivo, a través de la llamada cultura del diseño, que pone el foco sobre las necesidades creadas y no sobre las reales (Max Neef, 1993) incentivando la llamada Cultura del Simulacro (Baudrillard). Con el hipercapitalismo, el Diseño se ha convertido en un fenómeno global que ha gestado una nueva generación de consumidores de diseño, representado y descripto como foco del ocio, el consumo y el entretenimiento público (Guy Julier, 2010). La teoría de "necesidades y satisfactores" propone que las necesidades son finitas y universales, pero que las formas en que las personas satisfacen esas necesidades son ilimitadas y propias para su época, cultura, ubicación geográfica, edad y mentalidad. El Diseño ha construido y contribuido en gran medida en crear los actuales contextos y estilos de la vida contemporánea que signan nuestras necesidades y determinan nuestros modos de vida cotidiana, por eso resulta importante comprender cómo se desenvuelven las estrategias que organizan las necesidades de las personas para desarrollar soluciones sostenibles (Max Neef, 1993 y Kossoff, 2011)

Frente a las consecuencias -en parte gestadas por la cultura del diseño-previamente analizadas en los apartados I, II y III, este se está corriendo de manera cada vez más veloz del nivel de los productos físicos, objetos y las cosas (utilitarios), como de su aspecto más de- 
corativo (estilismo) debido a las urgencias y desafíos de la sostenibilidad. Manzini, propone una intervención "en las estrategias que determinan la calidad social y medioambiental de este mundo en permanente cambio" (Manzini 1998 en Julier 2010: 76-77), lo que implica que el Diseño, debe comenzar a moverse en los ámbitos de la gestión, para poner en juego la facultad del pensamiento sintético propio del Diseño (Dilnot 1982) revisando la mejor combinación entre lo factible, lo posible y lo deseable. Las ideas de Manzini vinculan Diseño con Futuro, y del mismo modo que el Diseño para la Transición, se orientan por un Diseño en evolución que contiene a las variables socio-ambientales.

Es también parte del actual escenario, que la palabra "Diseño" viene corriendo barreras que lo sitúan más allá de sus definiciones más tradicionales. Puede decirse que en las últimas tres décadas, el Diseño se viene expandiendo hacia contextos mucho más amplios relacionados con la creación de experiencias, servicios y sistemas, y a través del Diseño para la Transición está estableciendo puentes con otras disciplinas -que viajan en el eje de la Ciencia y las Humanidades-incorporando un tratamiento analítico de los problemas sistémicos, el Co-Diseño, la gestión colaborativa y el Diseño especulativo. De este modo está siguiendo un camino evolutivo descripto y anticipado por Buchanan, donde el Diseño ya no solo está centrado en la creación de productos, sino que orientado hacia reformulación de la naturaleza de estos productos, pueden ser símbolos comunicativos e imágenes (Diseño de $1^{\circ} \mathrm{Grado}$ ), objetos físicos (Diseño de $2^{\circ} \mathrm{Grado}$ ), la configuración de sistemas, entornos, ideas y valores (Diseño de $3^{\circ} \mathrm{Grado}$ ), pasando de los procesos materiales a los procesos inmateriales que involucran sistemas, relaciones y estructuras (Diseño de $4^{\circ} \mathrm{Grado}$ ), donde el cuarto nivel de Diseño es de tipo complejo, multidisciplinar, interviene sobre los circuitos de la cultura, sus transiciones socio-técnicas e involucra e incluye a todos los niveles anteriores (Buchanan 1998:1-18).

\section{Cierre}

Los artículos del presente Cuaderno, al igual que este trabajo, fueron desarrollados durante el primer año de la pandemia por Coronavirus (Covid19) iniciada a fines de 2019, y que desde mediados de marzo de 2020 ha quebrado el nivel de régimen de todos los niveles organizacionales de los países del globo, sin mediar aun soluciones que permitan avizorar el final de la situación. Posiblemente la destrucción de los hábitats naturales, la disminución de la biodiversidad y la alteración de los ecosistemas junto a la destrucción aproximada de la mitad de las selvas tropicales, en las que viven alrededor de dos tercios de todos los seres vivos del mundo, la sucesiva deforestación de selvas y pulmones verdes de la tierra, el creciente calentamiento global, el comercio y explotación de animales sin control, nuestros estilos de vida hiper-industrializados y los modelos que sustentan nuestros sistemas de organización económica, entre otras condiciones, han creado este temible desequilibrio de los ecosistemas, y el contexto propicio que estimula la proliferación de enfermedades y la gestación de virus, como el actual en curso.

Desde hace alrededor de más de 50 años hemos tenido tantas otras advertencias de la ciencia a través de informes y estudios, y otros muchos avisos naturales previos y paralelos relacionados 
con plagas, sequías, inundaciones, cataclismos, derretimiento de los polos, extinción de especies animales y vegetales, cambio climático, hasta llegar a esta pandemia cuyas características son excepcionales y asimilables a los trastornos que ocasiona una guerra...

Las pandemias suelen sucederse en lapsos de a 100 años aproximadamente, sin embargo si seguimos embarcados en mantener el actual paradigma, posiblemente comiencen a sucederse cada 50 o 30 años, que sumadas a las demás variables en desenvolvimiento nos pondrán en el terreno de gestionar crisis ad infinitum.

Debemos reflexionar y aprender de los actuales contextos y ponernos a educar para concientizar y cambiar los actuales modelos mentales hacia otros mejores más sostenibles y humanos.

\section{Notas}

1. Este escrito se basa en la Conferencia Virtual Experiencia Diseño en Perspectiva, Investigación en Gestión del Diseño, que quién escribe, expuso como invitada por el Profesor Doctor Mostafá Zekri, en la Universidad ISMAT, Instituto Superior Manuel Teixeira Gómes, Grupo Lusófona, Portimao, Portugal, frente al Departamento de Diseño, Profesores y Estudiantes el 30 de marzo de 2021. Disponible en: https://www.youtube.com/watch?v $=$ WbajTjXPdXY

2. http://donellameadows.org/archives/a-synopsis-limits-to-growth-the-30-year-update/ 3. "El término Antropoceno se emplea hoy en centenares de libros y artículos científicos, se cita miles de veces y se usa cada vez más en los medios de comunicación. Creado en un principio por el biólogo estadounidense Eugene F. Stoermer, este vocablo lo popularizo a principios del decenio de 2000 el holandés Paul Crutzen, premio Nobel de Química, para designar la época en la que las actividades del hombre empezaron a provocar cambios biológicos y geofísicos a escala mundial. Ambos científicos habían comprobado que esas mutaciones habían alterado el relativo equilibrio en que se mantenía el sistema terrestre desde los comienzos de la época holocena, esto es, desde 11.700 años atrás" (Rejane Issberner y Léna, 2018: 7, UNESCO 2018).

4. "Parece haber un consenso sobre el hecho de que varios parámetros del sistema terrestre han empezado a evolucionar fuera del espectro de variabilidad natural de la época holocena, y también se admite cada vez más el uso de la expresión época antropocena para especificar que esa evolución es de origen humano" (Rejane Issberner y Léna, 2018: 8 UNESCO 2018).

5. "Historiadores y antropólogos se han interrogado sobre la referencia al anthropos, esto es, al ser humano genérico. Y se preguntan si no son el hombre occidental y un determinado sistema económico los responsables de haber traspasado los límites biogeofísicos del planeta. Por eso se han propuesto otras denominaciones como Occidentaloceno o Capitaloceno" (Rejane Issberner y Léna, 2018: 8 UNESCO 2018).

6. "Agrupando todos esos datos, el sueco Johan Rockstrom y el estadounidense Will Steffen, junto con sus colegas del Centro de Resiliencia de Estocolmo, confeccionaron en 2009 y 2015 una lista con nueve límites del planeta que sería sumamente peligroso traspasar (...)” (Rejane Issberner y Léna, 2018: 8, UNESCO 2018). 
7. "Las ciencias humanas y sociales tendrán que elaborar y dominar instrumentos y conocimientos inéditos para responder a los problemas planteados por esta nueva era de la humanidad: desastres de la naturaleza, energías renovables, agotamientos de recursos naturales, desertificaciones, ecocidios, contaminaciones generalizadas, migraciones, injusticias sociales y medioambientales, etc.” (Rejane Issberner y Léna, 2018: 9, UNESCO 2018). 8. Este cambio de mentalidad se apoya en uno de los conceptos del Diseño para la Transición llamado "Holarquía" que significa que todas las entidades desde el nivel molecular y celular hasta el nivel planetario son una totalidad interrelacionada. Cada entidad (holón) es a la vez un todo en sí mismo, pero parte de un todo mayor y, por lo tanto, es semiautónomo o interdependiente con otros holones, así como auto-organizado y emergente. De esta manera, debemos entender a los seres humanos, los hogares, los barrios, las aldeas, los pueblos, las ciudades y las regiones, es decir en cadenas continuas de analogías y bucles causales más allá de las disciplinas académicas individuales y las partes interesadas, donde todas las entidades influyen, se interrelacionan, se repiten y circulan entre sí (Irwin T, 2004).

\section{Referencias}

Baudrillard, J. (1978). Cultura y Simulacro. Kairos.

Bleecker, J. (2009). Design Fiction. A short essay on design, science, fact and fiction. EEUU: Near Future Laboratory.

Boyer, B.; Cook, J. W. y Steinberg, M. (2015). In Studio: Recipes for systemic change. Sitra: Helsinki Design Lab.

Boehnert, J. (2019). Transition design and ecological thought. Buenos Aires: Centro de Estudios en Diseño y Comunicación, Cuaderno 73, Pp. 133-148. Facultad de Diseño y Comunicación, Universidad de Palermo.

Boserman, C. (2019). Rescatando los objetos epistémicos del diseño especulativo. Diseña, (14), 118-137. Doi: 10.7764/disena.14.118-137.

Buchanan, R. (1998). Problemas Perversos en el Pensamiento del Diseño. Colloque Recherche sur le Design: Incitations, Implications, Interactions (primer simposio universitario francés sobre la investigación del diseño llevado a cabo en Octubre de 1990) en la Universidad Tecnológica de Compiègne, Compiègne, Francia.

Capra, F. (2009). La trama de la vida. Una nueva perspectiva de los sistemas vivos. Barcelona: Editorial Anagrama.

Di Bella, D. V. (2020). Visiones del Diseño III Problematizar el Diseño para Comprender su complejidad. 4oProyecto de la Línea de Investigación No4 Diseño en Perspectiva (CMUUP). Buenos Aires: Centro de Estudios en Diseño y Comunicación, Cuaderno 105, Pp. 95-123 Facultad de Diseño y Comunicación, Universidad de Palermo (publicado en 2021).

Di Bella, D. V. (2019). Visionarios del Diseño. Visiones del Diseño, Diseñadores Eco-Sociales. 30Proyecto de la Línea de Investigación No4 Diseño en Perspectiva (CMU-UP). Buenos Aires: Centro de Estudios en Diseño y Comunicación, Cuaderno 87, Pp. 55-104. Facultad de Diseño y Comunicación, Universidad de Palermo (publicado en 2020). 
Di Bella, D. V. (2018). Informe de Impacto de la Experiencia Diseño en Perspectiva. Buenos Aires: Centro de Estudios en Diseño y Comunicación, Cuaderno 80, Pp. 173-239. Facultad de Diseño y Comunicación, Universidad de Palermo (publicado en 2020).

Dilnot, C. (1982). Design as a Socially Significant Activity: an Introduction. Design Studies Vol3.

Dorst, K. (2015). Frame Innovation: Create a New Thinking for Design. EEUU: The MIT Press.

Dunne, A. and Raby, F. (2013). Speculative Everything: Design, Fiction and Social Dreaming. The Mit Press.

Escobar, A. (2016). Autonomía y Diseño. La realización de lo comunal. Colombia: Universidad del Cauca.

Fry, T. (2004). “The Voice of Sustainment: The Dialectic" in Design Philosophy Journal. Disponible en: www.desphilosophy.com

Irwin, T.; Tonkinwise, C. \& Kossoff, G. (2015). Transition Design: An educational framework for advancing the study and design of sustainable transitions. Paper presented at the Sustainability Transitions Research Network Conference, Brighton, United Kingdom.

Irwin, T.; Kossoff, G. \& Tonkinwise, C. (2015). Transition Design Provocation. Design Philosophy Papers 13(1), pp. 3-11.

Irwin, T. (2018). The Emerging Transition Design Approach. Irlanda: University of Limerick.

Irwin, T. (2017). Transition Ojai: A Water Security Workshop. En materiales provistos para el Workshop de la School of Design at Carnegie Mellon. Ojai, May 5 - 6 California.

Irwin, T. (2017). The Emerging Transition Design Approach. Buenos Aires: Centro de Estudios en Diseño y Comunicación, Cuaderno 73, Pp. 149-181. Facultad de Diseño y Comunicación, Universidad de Palermo (publicado en 2019).

Irwin, T. (2015). Transition Design: A Proposal for a New Area of Design Practice, Study, and Research. UK: Taylor and Francis online. Design and Culture. The Journal of the Design Studies Forum. Vol7. Issue 2. pp 229-246. Disponible: http://dx.doi.org/10.108 0/17547075.2015.1051829

Irwin, T. (2011). Wicked Problems and the Relationship Triad. In Stephan Harding (ed.), Grow Small, Think Beautiful: Ideas for a Sustainable World from Schumacher College. Edinburgh: Floris Books.

Irwin, T. (2004). Extracts: Living Systems Principles and Their Relevance to Design. En: MSc Thesis, Holistic Science: Holistic Design. pp. 22-66 Schumacher College/University of Plymouth, Devon England, 2004

Julier, G. (2010). La cultura del diseño. Barcelona: Gustavo Gili.

Kirby, D. A. (2010). The Future Is Now: Diegetic Prototypes and the Role of Popular Films in Generating Real-World Technological Development. Social Studies of Science · February 2010. Disponible en: https://www.researchgate.net/publication/249721702.

Kossoff, G. (2011). Holism and the Reconstitution of Everyday Life: A Framework for Transition to a Sustainable Society. In: Harding, Stephan, ed. Grow Small, Think Beautiful. Edinburgh (UK): Floris Books.

Lockton, D. \& Candy, S. (2018). A Vocabulary for Visions in Designing for Transitions. Buenos Aires: Universidad de Palermo. En Diseño en Perspectiva-Diseño para la Transición: 
Primera sección en Cuaderno ${ }^{\circ} 73$ del Centro de Estudios en Diseño y Comunicación. Facultad de Diseño y Comunicación (publicado en 2019)

Manzini, E. (2015). Design, When Everybody Designs. An Introduction to Design for Social Innovation. EEUU: The MIT Press.

Manzini, E. \& Jegou, F. (2003). Sustainable Every Day. Scenarios of Urban Life. Italia: Edizioni Ambiente, Milan. Fondazione La Triennale di Milano.

Max Neef, M. (1993). Desarrollo a escala humana. Conceptos, aplicaciones y algunas reflexiones. Uruguay: Editorial Nordan-Comunidad.

Meadows, D. (2009). Leverage Points: Places to Intervene in a System. Solutions Journal. Available online: http://www.thesolutionsjournal.com/node/419.

Naredo Perez, J. M. (2004). Sobre el origen, el uso y el contenido del término sostenible. En: Cuadernos de investigación urbanística, ISSN 1886-6654, No41, 2004 (Textos sobre sostenibilidad I) pp. 7-8. Disponible en: http://dialnet.unirioja.e s/servlet/articulo? codigo $=1333758$.

Orr, D. W. (2002). The Nature of Design - Ecology, Culture, and Human Intention, Oxford University Press.

Orr, D. (2018). The political economy of design in a hotter time. In R. B. Egenhoefer (Ed.), Routledge handbook of sustainable design (pp. 3-10). London, England: Routledge.

Orr, D. (1992). Ecological literacy. Albany: State University of New York Press.

Rittel, H. \& Webber, M. (1973). Dilemmas in a General Theory of Planning. Working Papers from the Urban \& Regional Development, University of California Berkeley.

Sanders, E. y Stappers, P. J. (2008). Co-creation and the New Landscapes of Design. Taylor and Francis Group: CoDesign Vol 4, N ${ }^{\circ}$ 1, March 2008, 5-18. Disponible en: https://www. researchgate.net/publication/235700862

Thackara, J. (2005). In the buble: Designing in the complex world. Londres: The MIT Press Cambridge, Massachusetts

UNESCO (2018). Bienvenidos al antropoceno. El Correo de la UNESCO Abril-Junio. EEUU: Organización de las Naciones Unidas para la Educación, la Ciencia y la Cultura.

\section{Bibliografía}

Cuadernos del Centro de Estudios en Diseño y Comunicación que integran la Línea de Investigación No4 Diseño en Perspectiva, junto a la presente Edición.

Cuaderno del Centro de Estudios en Diseño y Comunicación No105. (2020) (Publicado en 2021) Visiones del Diseño III: Problematizar el Diseño para Comprender su Complejidad. Coordinación Daniela V. Di Bella (UP) y Terry Irwin (CMU). Facultad de Diseño y Comunicación Año XXIII, Buenos Aires, Argentina. ISSN: 1668-0227.

Cuaderno del Centro de Estudios en Diseño y Comunicación No87. (2019) (Publicado en 2020) Visiones del Diseño II: Diseñadores Eco-Sociales. Coordinación Daniela V. Di Bella (UP) y Terry Irwin (CMU). Facultad de Diseño y Comunicación Año XXI, Buenos Aires, Argentina. ISSN: 1668-0227. 
Cuaderno del Centro de Estudios en Diseño y Comunicación No80. (2018) (Publicado en 2020) El Visiones del Diseño I. El Diseñador como Agente de Cambio. Diseño en Perspectiva - Diseño para la transición. Segunda Sección. Coordinación Daniela V. Di Bella (UP) y Terry Irwin (CMU). Facultad de Diseño y Comunicación Año XXI, Buenos Aires, Argentina. ISSN: 1668-0227.

Cuaderno del Centro de Estudios en Diseño y Comunicación No73. (2017) (Publicado en 2019) Diseño en Perspectiva - Diseño para la transición. Primera Sección. Coordinación Terry Irwin (CMU) y Daniela V. Di Bella (UP). Facultad de Diseño y Comunicación Año XIX, Buenos Aires, Argentina. ISSN: 1668-0227.

\begin{abstract}
Design has become a global phenomenon, with a high power of social and cultural persuasion (Julier, 2008), which together with its own modeling of the type of thinking that the design has, and the power of anticipatory visions, can influence the social and technical transitions towards sustainable lifestyles and settings. This publication is the fifth Journal of Research Line No4 Design in Perspective, Design Scenarios, and belongs to Project No5 called Visions of Design: Design as a Third Culture. It continues the inquiries cited from the most recent: Problematize Design to Understand its Complexity (Project 4: Journal 105. Di Bella, 2020: 95-123) and the need to problematize Design as part of the systemic understanding of its nature, its impacts, and the change of scale of problems in Design Management; Eco-Social Designers, and the exploration of potentially useful lenses for the development of visions of sustainable futures (Project 3: Journal 87. Di Bella, 2019: 55-104), The Designer as an agent of change (Project 2: Journal 80. Di Bella, 2018: 173-239 and Project 1: Journal 73. Irwin and Di Bella, 2017). It continues the path of reflection and research linked to the Transition Design Program of Carnegie Mellon University, within the Master in Design Management-UP along with its joint publication actions and shared direction that opens a fifth study period of the implementation of the Experience.
\end{abstract}

Keywords: Design - Future - Design Visions - Design for Transition - Sustainability Design Culture - Third Culture - Eco-literacy - Socio-technical Transitions - Prospective - Design Research - Design Theory.

Resumo: O design tornou-se um fenômeno global, com alto poder de persuasão social e cultural (Julier, 2008), que, juntamente com seu próprio modelo de pensamento de design, e o poder de visões antecipatórias, podem influenciar as transições sociais e técnicas em direção à sustentabilidade. estilos de vida e configurações. Esta publicação é o quinto Caderno da Linha de Pesquisa No4 Design em Perspectiva, Cenários de Design, e pertence ao Projeto No5 denominado Visões do Design: O Design como Terceira Cultura. Dá continuidade às indagações citadas do mais recente: Problematizar o Design para Entender sua Complexidade (Projeto 4: Caderno 105. Di Bella, 2020: 95-123) e a necessidade de problematizar o Design como parte da compreensão sistêmica de sua natureza, seus 
impactos , e a mudança de escala de problemas em Design Management; Eco-Social Designers, e a exploração de lentes potencialmente úteis para o desenvolvimento de visões de futuros sustentáveis (Projeto 3: Caderno 87. Di Bella, 2019: 55-104), O Designer como um agente de mudança (Projeto 2: Caderno 80 . Di Bella, 2018: 173-239 e Projeto 1: Caderno 73. Irwin e Di Bella, 2017). Continua o caminho de reflexão e pesquisa vinculado ao Transition Design Program da Carnegie Mellon University, no âmbito do Master in Design Management-UP juntamente com as suas ações de publicação conjunta e direção compartilhada que abre um quinto período de estudo da implementação da Experiência.

Palavras chave: Design - Futuro - Visões do design - Design para a transição - Sustentabilidade - Cultura do design - Terceira cultura - Ecoalfabetismo - Transições sociotécnicas - Prospectiva - Pesquisa em design - Teoria do design. 